\section{OPEN $\bigcirc$ ACCESS}

Authors' contribution:

A) conception and design of the study

B) acquisition of data

C) analysis and interpretation of data

D) manuscript preparation

E) obtaining funding

\title{
Socioecological Profile of Active Adults. Sport as a Whole-life Choice
}

\author{
Elżbieta Biernat $^{1 \mathrm{~A}-\mathrm{E}}$, Łukasz Skrok $^{1 \mathrm{~A}-\mathrm{D}}$, Dawid Majcherek ${ }^{1 \mathrm{~A}-\mathrm{D}}$, \\ Hanna Nałęcz ${ }^{2 A-D}$ \\ ${ }^{1}$ SGH Warsaw School of Economics, Poland \\ ${ }^{2}$ Institute of Mother and Child, Poland
}

ABSTRACT

Hitherto empirical research provides insight on particular dimensions or aspects thereof, but analyses that include diverse determinants of the physical activity are scarcer. The aim of the research was to examine the profile of adults who engage in sport activity, using a multi-layer, socio-ecological approach. Combined database: The Social Diagnosis 2015, The Statistics Poland 2014, and the Orliki 2012 was applied. The resulting sample consists of 8,361 adult respondents aged 25-70 years. Sport activity and sport clubs' membership were measured as dependent variables. According to the Bronfenbrenner's layered model number of outcome variables were described. While being consistent with fundamental facts known from the literature (e.g. significance of age, education, family, social networks and cultural aspects, the results point to a heterogeneity in determining sport activity. Firstly, women and men differ qualitatively - the set of characteristics important for sport activity is different. For example, while minor health issues seem to instigate activity of women, for men they are rather negatively related. Secondly, different factors are relevant for initiating the activity than for sustaining it. Furthermore, sport activity is rather positively related to other activities related to social life or to the life-long learning. This suggests that a substitution effect, in terms of time, is less important than the general tendency to be engaged in different aspects of life. Lastly, active membership of sports clubs is not only rare, but also qualitatively differs from sports activity in terms of socio-ecological profile of the participants. The obtained results emphasize the need to create and implement nuanced and varied policies to support increase in physical activity in modern societies. Traditional, 'hard' measures like providing physical (facilities) or organisational (sports clubs) infrastructure seem to have limited effectiveness.

KEYWORDS physical activity, determinants of sport activity, membership of sports clubs, public health, Poland

\section{Introduction}

World Health Organization (WHO) in health enhancing physical activity (HEPA) guidelines, recommends increasing participation in sport - as one of the main goals of achieving the desired change in behaviour (World Health Organization, 2018). Its significance is noticed by governments around the world by setting as a priority objective of their actions to increase the level of sport activity (SA), physical activity (PA) (Resolution of the Council), and concerns about health (Grima et al., 2018). Because of these activities, and as a result of changes in people's consciousness and lifestyle during the second half of XX century in Europe, the significant increase in the number of people declaring SA and increasing its frequency was noticed (Scheerder \& Vos, 2011). 
However, at the same time, still about $60 \%$ of Europeans do not play sport at all or do it too rarely (European Commission, 2010).

Modern strategies focused on increasing sports and PA, require better understanding and applying factors leading to objectives achievement defined by Downward (2007) as 'the fulcrum and/or target'. Additional information about behaviour patterns and user preferences is needed, and not only on those who train in sports clubs, but also on non-members tending to exercise in gyms, health centres, swimming pools or those who engage in an informal sport setting, e.g. outdoor gyms in public space (Deelen, Ettema \& Kamphuis, 2018).

Several theoretical models explaining involvement in sport were developed, i.e. The Beckerian Approach (Becker, 1974) The SLOTH framework (Cawley, 2004) and Green's Model of Sport Development (Green, 2005). On that basis key determinants of participation in sport were described (Hallmann et al., 2011). Becker's economic theory made background for A Sport Participation Model. This theory and model were further developed to include several demographic and social variables and has been used in the numerous of research (Hallmann et al., 2012). The socioecological model developed by Bronfenbrenner presents multi-disciplinary approach, focusing on the holistic environment as a chain of nested structures, and assumes that people are closely related to the environment and are influenced by it (Bronfenbrenner \& Morris, 2006).

Therefore, understanding individual human behaviour requires looking not only at individual or sociodemographic traits, but also at the whole environment - as five overlapping layers: individual, micro-, meso-, exo- and macrosystem. The first layer consists of individual factors, e.g. gender, age, nationality, personality traits. The second layer are factors related to the direct environment, e.g. relationships with family members, in the workplace, classroom, neighbourhood, or with peers. The mesosystem concerns the relationship between associated micro-systems, such as: family home, neighbourhood and school. The next layer (exosystem) refers to the supporting environment, including formal and physical features, such as: sports facilities, parks, recreation centres, sports clubs and places important for the local community. The last, most general, external layer (macro) allows to describe the consistency of the form and content of lower layers (micro-, meso- and exosystem) from the level of the whole society. It covers the overriding values and customs of cultures and societies as well as general socio-economic and cultural conditions.

Bronfenbrenner's socio-ecological approach is widely used in health promotion (Cochrane, \& Davey, 2008). But it is rarely used as a whole in the analysis of the sport activity, e.g. in the study of Van Tuyckom (2011), only the macro layer is referred to.

Based on the socio-ecological model, the aim of our analysis was to answer the question: Which characteristics distinguish adults engaged in SA from passive ones? Moreover, does the more intense and more socially engaging form - membership of sports clubs - differ in this respect? Importantly, the Polish Social Diagnosis dataset allowed us to analyse a multidimensional aspect of labour, social, health and cultural profiles. According to the current knowledge, this type of study was carried out for the first time. The authors hope that it will build the foundations for future research, which may play an important role in both policy design as well as in maintaining the right investments in the sport for all. The study was conducted as part of the project No. 2017/27/B/HS4/00427 ,The role of sport activity in building social capital in Poland” funded by the National Science Centre, Poland, and conducted in the Warsaw School of Economics.

\section{Methods}

Three datasets were combined to conduct analysis:

1. The Social Diagnosis (SD) by Council for Social Monitoring (2015): a longitudinal study on conditions and quality of life in Poland that had been conducted between 2000 and 2015 (usually biannually) among individuals older than 15 years (Czapiński \& Panek, 2015) - dataset consists of information on individuals (including SA, and membership of sports clubs) and their households; 
2. The Statistics Poland (SP) data on sports infrastructure (except for school facilities) based on study using forms officially called KFT-OB and KFT-1 (Statistics Poland, 2014) the study is conducted every four years with the latest available being 2014; the data includes type and year of the infrastructure construction;

3. the Orliki database - containing information on facilities constructed in 2008-2012 within a programme co-financed by the central and local government, which aimed to build a modern, free-of-charge complex of football/basketball/multipurpose fields, locker-rooms etc. in all municipalities in Poland (Biernat, Piątkowska \& Zembura, 2017).

Combination of the datasets has been conducted on the most precise level possible, which is NUTS 3 - in Poland stands for sub-regions, which are solely used for statistical purposes and do not constitute a part of local government system. We used the most recent data for the analysis: for the $S D$ - from 2015; the Statistics Poland data from 2014; and all the Orliki facilities were constructed by 2012.

For a dependent variable we adopt sport activity (SA), defined according to the concept used in SD as follows 'Do you practice any sport or PA?:' and the set of possible answers: 1. no, I do not practice any sport or PA; 2. aerobics; 3. running/jogging/Nordic walking; 4. gym; 5. cycling; 6. skiing or other winter sports; 7. swimming; 8. football or other team sports; 9. yoga; 10. martial arts; 11. another sport or type of PA. The defined answers and lack of activities categories like walking, dancing or performing household chores among them, suggest that PA in SD was understood in the narrow sense, as SA, but not as sport following the Glossary of Global action plan on physical activity 2018-2030: more active people for a healthier world (WHO 2018) definition. In our sample, $47 \%$ of respondents declared SA of at least one type within this multichoice question.

We have selected a sample of individual respondents being 25-70 years old (at the moment of the SD 2015 being conducted). Firstly, it allows to omit people in the 'traditional' student age (19-24), who, if being fulltime students, can be obligated to participate in physical education classes. Secondly, it contains the youngest retiring people (not only using early retirement schemes), for whom it is interesting to see whether an increase in the amount of free time might result in raised SA. Respondents who have not answered the question about SA, were omitted. The resulting base sample consists of 8,361 respondents. The descriptive statistics are reported in the Additional file 1 (Supplementary Table 3-5).

It is important to note that while $47 \%$ respondents of our sample engaged in SA, the membership in sports club was very rare - less than $1.5 \%$ of the respondents included in the sample were active members (Supplementary Table 5). Furthermore, majority experienced physical or health in the previous months (Supplementary Table 5). In this context it is important to note, that that there was an issue of overweight (average BMI is 26.3; Supplementary Table 3, Additional file 1) and that the average age was 44.8 (Supplementary Table 3).

The analysis was based on eight logit models explaining propensity to engage in SA or being an active member of a sports club. Due to abundance of variables (majority of which are dummy variables), we have omitted interactions of variables from the models, while the crucial differences in the process of determining SA between a) men and women, b) people previously engaged in SA or not, have been illustrated by separate logit regressions, estimated using relevant subsamples. While the formal causal analysis is not an aim of this article, supplementary analysis of previously passive and active subsamples allows us to draw conclusions that go beyond contemporaneous correlations.

In case of the sports clubs' membership, two separate models have been estimated - one includes variables on the sports disciplines declared by the respondents, while the other does not. The rationale behind including these two models is that the several disciplines would strongly determine membership of the sports club and, while being determined by underlying socio-ecological characteristics, would dominate the latter. Since it does not happen, the first model has been reported only in the Supplementary Tables 6-8, Additional file 1. The ordered probit/logit regressions, on the other hand, proved inappropriate due to rejection of the parallel regression assumption. The latter, along with reported results, shows variation of both analysed processes (determining 
$\mathrm{SA} /$ membership of sports clubs). Furthermore, very low participation rate of women $(0.6 \%$ in the base sample declare active membership of sports clubs) and evident differences between women and men in terms of determining SA led to limitation of the sample to men only ( $2.5 \%$ men are members).

Due to high number of variables and, on the other hand, multi-layered theoretical model underlying the analysis, estimated coefficients have been divided into several groups and presented separately, the results are summarized in tables 1-3. Each column presents different model specification, whereas the particular specifications contained complete sets of variables. The tables contain variables that can be assigned to particular levels of the Bronfenbrenner theory, starting from the individual level. Odds ratios and significance level are reported with 95\% confidence intervals for the significant coefficients within the text. Furthermore, the variables coefficients that are not significant for the lowest critical values within the baseline regression models have been reported only in the Supplementary Table 9, Additional File 1. The reported standard errors are clustered by households. To examine the robustness of our results and, having the issue of dependence between people from the same household, we have also estimated and reported a model for a randomly drawn subsample, consisting of only one person per household (denoted as 'Sports: random subsample'), Additional File 1.

\section{Results}

In terms of individual characteristics (table 1), qualitative differences between two genders occur. One of the few exceptions concerns age - the older the respondent was, the less likely was the engagement in SA was being one year older meant odds of engaging in SA decreasing by $1.1 \%$ for women (OR: $0.989,95 \%$ CI: 0.979, 0.999 ) and $2.1 \%$ for men (OR: 0.979, 95\% CI: 0.969, 0.990). Furthermore, for men education correlates with SA positively. Each year of education increases odds by 6.6\% (OR: 1.066, 95\% CI: 1.012, 1.123), while being able to use English language by $26.9 \%$ (OR: $1.269,95 \%$ CI: 1.003, 1.606). For women, no significant impact of education can be observed.

Men and women also differ in terms of relation between health and SA. In particular, the odds ratio of SA gets lower for women when BMI increases (OR: 0.977, 95\% CI: 0.962, 0.993). Having any disability also means lower odds for women (OR: 0.726, 95\% CI: 0.552, 0.955). SA also coincides with higher satisfaction with one's health for women (OR: $0.850,95 \%$ CI: $0.783,0.921)$. On the other hand, women tend to be active more often, when: sometimes (but not often) had suicidal thoughts (OR: 1.540, 95\% CI: 1.171, 2.027); were seriously ill the previous year (OR: 1.416, 95\% CI: 1.094, 1.832); at least once in the recent months had health problems that made it difficult to perform everyday activities or to take part in other activities (OR: $1.257,95 \%$ CI: 1.028 , 1.538); have had attacks of excessive sweating for more than 15 days a month (OR: $1.604,95 \%$ CI: 1.155 , 2.230). Conversely, shortness of breath means a lower propensity towards $S A$ (if occurred for less than 15 days a month OR: $0.748,95 \%$ CI: 0.603, 0.927; if more often, OR: 0.603, 95\% CI: $0.366,0.993$ ), as well as an often tiredness not related to work (OR: 0.687, 95\% CI: 0.490, 0.965).

For men, often having ailments making it difficult to leave home, climb stars etc. means lower odds (OR: 0.752, 95\% CI: $0.598,0.945$ ) of SA. Men also tend to be less active when they are losing interest in sex (OR: 0.666 , 95\% CI: 0.540, 0.822). Moreover, active membership in sports clubs coincides with having often chest or heart pains (OR: 19.7, 95\% CI: 1.707, 227.350). On the other hand, an often tiredness not related to work mean lower odds of SA (OR: $0.035,95 \%$ CI: $0.004,0.313$ ).

Additional insight could be drawn from separate analysis of two subsamples - people engaged in SA (or not) in 2013. Physical problems coincide with lower odds of SA for the previously active respondents (OR: 0.678, $95 \%$ CI: $0.505,0.909)$. In case of previously passive respondents, serious illness in the previous year coincide with higher odds of SA (OR: 1.693, 95\% CI: 1.195, 2.399), whereas dissatisfaction with health with lower odds (OR: 0.787, 95\% CI: 0.702, 0.882). 
A second characteristic for which there is no qualitative difference between the two genders in terms of SA is smoking - the odds go down by $2.3 \%$ for each cigarette smoked per day for both women (OR: $0.977,95 \% \mathrm{CI}$ : 0.964, 0.990) and men (OR: 0.976, 95\% CI: 0.965, 0.986). Furthermore, with one additional hour per week spent on reading newspapers, magazines etc. odds for women increase (OR: 1.018, 95\% CI: 1.001, 1.036).

Table 1. Logistic regression modelling of sport activity (coefficients for the individual variables)

\begin{tabular}{|c|c|c|c|c|c|c|}
\hline Variable & $\begin{array}{c}\text { Sports: } \\
\text { whole sample }\end{array}$ & $\begin{array}{l}\text { Sports: } \\
\text { women }\end{array}$ & Sports: men & $\begin{array}{c}\text { Sport } \\
\text { clubs: men }\end{array}$ & $\begin{array}{c}\text { Sports: } \\
\text { passive in } \\
2013\end{array}$ & $\begin{array}{c}\text { Sports: } \\
\text { active in } \\
2013\end{array}$ \\
\hline Woman & 0.936 & & & & 1.141 & 0.835 \\
\hline Age & $0.985 * * *$ & $0.989 *$ & $0.979 * * *$ & 0.998 & $0.978 * *$ & 1.000 \\
\hline Education (years) & $1.05 * *$ & 1.033 & $1.066^{*}$ & 1.08 & 1.059 & 1.061 \\
\hline Higher Education & 1.019 & 1.087 & 1.072 & 0.512 & 0.875 & 1.081 \\
\hline English & $1.158 *$ & 1.089 & $1.269 *$ & 0.508 & 1.192 & 1.333 \\
\hline Physical problems & 0.873 & 0.956 & $0.752 *$ & 0.543 & 1.194 & $0.678 *$ \\
\hline Health problems & $1.164^{*}$ & $1.257 *$ & 1.045 & 1.401 & 1.007 & 1.335 \\
\hline $\mathrm{BMI}$ & $0.981 * *$ & $0.977 * *$ & 0.984 & 0.983 & 0.987 & 0.977 \\
\hline Disability & $0.795^{*}$ & $0.726 *$ & 0.88 & 1.369 & 1.01 & 0.678 \\
\hline $\begin{array}{l}\text { Dissatisfaction with } \\
\text { health }\end{array}$ & $0.889 * * *$ & $0.850 * * *$ & 0.929 & 0.863 & $0.787 * * *$ & 0.936 \\
\hline Rare suicidal & $1.277 *$ & $1.540 * *$ & 0.93 & 2.11 & 1.189 & 0.887 \\
\hline Often suicidal & 0.892 & 0.937 & 0.776 & 1.52 & 0.867 & 0.876 \\
\hline Seriously ill & 1.204. & $1.416 * *$ & 1.062 & 0.321 & $1.693 * *$ & 0.952 \\
\hline Sleeping problem & 1.207 & 1.086 & 1.415 & 1.125 & 1.131 & 1.532 \\
\hline Less interest, sex & $0.784 * * *$ & 0.865 & $0.666 * * *$ & 0.69 & $0.726^{* *}$ & 0.805 . \\
\hline $\begin{array}{l}\text { Pain in neck/arm } \\
\text { muscles }(<1 / 2)\end{array}$ & 0.936 & 0.862 . & 1.036 & 0.796 & 1.019 & 0.874 \\
\hline $\begin{array}{l}\text { Pain in neck/arm } \\
\text { muscles }(>1 / 2)\end{array}$ & 1.069 & 1.045 & 1.193 & 3.425 & 1.122 & 0.892 \\
\hline Chest/heart pains $(<1 / 2)$ & 1.003 & 0.991 & 1.047 & 1.924 & 0.978 & 0.965 \\
\hline Chest/heart pains $(>1 / 2)$ & 0.957 & 1.008 & 0.975 & $19.7 *$ & 0.94 & 1.076 \\
\hline Sweating $(<1 / 2)$ & 1.126 & 1.131 & 0.996 & 1.653 & 0.951 & 1.358 \\
\hline Sweating $(>1 / 2)$ & $1.578 * *$ & $1.604 * *$ & 1.367 & 1.031 & $1.779 *$ & 1.585 \\
\hline Breath $(<1 / 2)$ & $0.826^{*}$ & $0.748 * *$ & 1.006 & 2.019 & 0.946 & 0.719 . \\
\hline Breath $(>1 / 2)$ & $0.64^{*}$ & $0.603 *$ & 0.75 & 0.971 & 0.505 & 0.974 \\
\hline Shivers $(<1 / 2)$ & 0.88 & 0.839 & 1.009 & 0.192 . & 1.146 & 0.67 \\
\hline Shivers $(>1 / 2)$ & 1.099 & 1.077 & 0.855 & 9.503 & 0.961 & 3.924. \\
\hline Bladder $(<1 / 2)$ & 1.133 & 1.136 & 1.065 & 0.744 & 1.18 & 1.202 \\
\hline Bladder $(>1 / 2)$ & $1.472 *$ & 1.364 & 1.753 & 0.988 & 1.692 . & 1.067 \\
\hline Tiredness $(<1 / 2)$ & 1.091 & 1.086 & 1.141 & 0.76 & 1.21 & 1.094 \\
\hline Tiredness $(>1 / 2)$ & $0.732 *$ & $0.687 *$ & 0.962 & $0.035^{* *}$ & 0.86 & 0.878 \\
\hline Constipation $(<1 / 2)$ & 1.016 & 1.005 & 1.052 & 0.536 & 0.91 & 1.004 \\
\hline Constipation $(>1 / 2)$ & 1.022 & 0.877 & 1.977 & 1.057 & 0.957 & 0.984 \\
\hline Number of cigarettes & $0.977 * * *$ & $0.977 * * *$ & $0.976 * * *$ & 0.968 & $0.984^{*}$ & $0.968 * * *$ \\
\hline Drugs & 1.091 & 2.269 & 0.902 & 5.492 & 0.493 & 2.161 \\
\hline Time for press & $1.019 * *$ & $1.018 *$ & 1.018 & 0.944 & $1.027 *$ & 1.011 \\
\hline Goals $>$ fun & $1.122 *$ & $1.167 *$ & 1.087 & 1.168 & 1.131 & 1.075 \\
\hline $\begin{array}{l}\text { Fun: the most important } \\
\text { thing }\end{array}$ & $1.167 * *$ & $1.242 * *$ & 1.083 & 0.618 & 1.095 & 1.065 \\
\hline $\begin{array}{l}\text { Life delightful or } \\
\text { pleasing }\end{array}$ & $0.877 *$ & $0.846^{*}$ & 0.89 & 1.153 & 0.851 & 0.843 \\
\hline Energy to work & $1.259 * *$ & $1.301 * *$ & $1.279 *$ & 1.082 & 1.15 & 1.025 \\
\hline Reforms in Pl successful & 1.135. & 1.132 & 1.161 & 0.946 & 1.043 & 1.237 \\
\hline Observations & 8,361 & 4,580 & 3,781 & 1,674 & 3,366 & 2,527 \\
\hline Pseudo $\mathrm{R}^{2}$ & 0.174 & 0.157 & 0.240 & 0.334 & 0.150 & 0.164 \\
\hline
\end{tabular}

Note: The table reports odds ratio. Significance: $* * *<0.001, * *<0.01, *<0.05, .<0.1$

Source: own study 
When it comes to attitudes towards life, women tend to be active more often when they think that achieving goals is more important than having fun (OR: 1.167, 95\% CI: 1.003, 1.357) and when they agree that 'a lot of fun is the most important thing in life' (OR: 1.242, 95\% CI: 1.073, 1.438). Moreover, being 'delighted' or 'pleased' with one's entire life decreases the odds of SA (OR: 0.846, 95\% CI: 0.729, 0.983). Lastly, for both genders one can observe similar relation between SA and having undiminished energy to work (for women OR: 1.301, 95\% CI: 1.089, 1.556; for men OR: 1.279, 95\% CI: 1.014, 1.612).

Family situation significantly impacts engagement in SA (table 2). Being married means lower odds of SA for men (OR: 0.646, 95\% CI: 0.512, 0.815). Furthermore, number of children and adults in the household has a negative impact, albeit the former only in case of women. They odds of sport activity decrease by $26 \%$ for each child under 5 (OR: $0.740,95 \%$ CI: $0.625,0.875$ ) and by $24 \%$ for each between 5 and 9 (OR: $0.764,95 \%$ CI: $0.665,0.878)$. In case of number of adults, the negative effect takes place both for women (OR: $0.880,95 \% \mathrm{CI}$ : $0.832,0.931$ ) and for men (OR: $0.917,95 \%$ CI: 0.858, 0.980). Furthermore, men that feel responsible for welfare and care for elder parents or other relatives have higher odds of SA (OR: 1.285, 95\% CI: 1.092, 1.512). Also, engagement of other family members in SA matters. For women in households in which all the other people over 19 are active the odds of SA are more than three times bigger than for household in which there is no other adult being active (OR: 3.142, 95\% CI: 2.665, 3.703). For men this effect might be even stronger (OR: 4.325, 95\% CI: 3.564, 5.248). Furthermore, this effect can be observed for both previously passive (OR: 3.198, 95\% CI: $2.524,4.053$ ) and previously active respondents (OR: 2.544, 95\% CI: 1.969, 3.286).

SA coincides with active social life - with every instance (per month) of involvement in religious meetings odds increased by $3.1 \%$ for women (OR: $1.031,95 \%$ CI: $1.005,1.058$ ) and by $4.2 \%$ for men (OR: $1.042,95 \%$ CI: $1.004,1.082$ ). Odds of SA rose by $11.6 \%$ for women (OR: $1.116,95 \%$ CI: $1.007,1.236$ ) or by $31.6 \%$ for men (OR: 1.316, 95\% CI: 1.122, 1.543) for each instance of going out to a cinema, theatre, for a concert etc. (per month); further, for women, the positive relation of SA with going to a restaurant, café or a pub (OR: 1.057, 95\% CI: $1.003,1.113$ ) and to social meetings (OR: 1.084, 95\% CI: 1.046, 1.124) was observed. For every acquaintance met regularly odds for men rose by 1\% (OR: 1.013, 95\% CI: 1.003, 1.024). Also, taking part in public meetings (not related to work) meant higher odds of SA for men (OR: 1.410, 95\% CI: 1.135, 1.751), as did voluntary activities for women (OR: 1.274, 95\% CI: 1.083, 1.498). Having worked for the benefit of local communities increased odds of SA for men (OR: 1.290, 95\% CI: 1.011, 1.647).

For women, safe social environment is important as well - having often been in fear because of crime, drug addiction and hooliganism in one's district, housing estate or neighbourhood meant $39.1 \%$ lower odds (OR: $0.609,95 \%$ CI: $0.420,0.881$ ).

Conversely to family members (odds go down by $5.4 \%$ for each family member; OR: $0.946,95 \%$ CI: 0.909 , 0.984 ), being a member of a sports club was positively related to the number of regularly met acquaintances (OR: 1.032, 95\% CI: 1.012, 1.053). This is further reinforced by positive relations to participation in public meetings (odds are almost tripled; OR: 2.915, 95\% CI: 1.511, 5.626), but also working for the benefit of local communities (odds more than quadruple; OR: 4.489, 95\% CI: 2.251, 8.953).

For most of the variables describing the labour market status, the effects are insignificant. Women who have retired and remained inactive in the labour market have 55.9\% higher odds of SA (OR: $1.559,95 \%$ CI: 1.011 , 2.403).

With the referential category being technicians and associate professionals, both 'higher' (at least in terms of average income) groups (Managers and Officials; Professionals) and 'lower' (Clerical support, Plant/machine operators and Farmers) have lower odds of SA (between 32.4\% - for Plant/machine operators, OR: 0.676, 95\% CI: $0.489,0.933$, and $57.3 \%$ - for Managers, OR: 0.427, 95\% CI: 0.288, 0.633). A similar effect is not seen in case of women. Furthermore, whereas the negative impact on odds of being a Farmer (OR: $0.584,95 \%$ CI: $0.369,0.927$ ) or a Plant/machine operator (OR: $0.595,95 \%$ CI: $0.395,0.895$ ) in case of previously passive 
respondents, for Professionals it is seen rather in case of previously active ones (OR: $0.679,95 \%$ CI: 0.475 , 0.970).

Table 2. Logistic regression modelling of sport activity (coefficients for the microsystem variables)

\begin{tabular}{|c|c|c|c|c|c|c|}
\hline Variable & $\begin{array}{l}\text { Sports: whole } \\
\text { sample }\end{array}$ & $\begin{array}{l}\text { Sports: } \\
\text { women }\end{array}$ & Sports: men & $\begin{array}{l}\text { Sport clubs: } \\
\text { men }\end{array}$ & $\begin{array}{l}\text { Sports: } \\
\text { passive in } \\
2013\end{array}$ & $\begin{array}{c}\text { Sports: } \\
\text { active in } \\
2013\end{array}$ \\
\hline Married & $0.777 * * *$ & 0.853 & $0.646^{* * *}$ & 1.281 & 0.844 & 0.918 \\
\hline Number of children $(0-4)$ & $0.796^{* * *}$ & $0.740 * * *$ & 0.870 & 0.476 & 0.894 & 0.783 . \\
\hline Number of children (5-9) & $0.841 * * *$ & $0.764 * * *$ & 1.011 & 0.84 & 1.028 & $0.747 * *$ \\
\hline $\begin{array}{l}\text { Number of teenagers } \\
(10-14)\end{array}$ & $0.901 *$ & 0.935 & 0.860 & 0.815 & 0.978 & 0.924 \\
\hline $\begin{array}{l}\text { Number of teenagers } \\
(15-19)\end{array}$ & 0.961 & 0.957 & 0.981 & 1.105 & 0.835 & 1.088 \\
\hline Number of adults & $0.894 * * *$ & $0.880 * * *$ & $0.917 *$ & 1.048 & 0.955 & 0.922 . \\
\hline Higher education, father & $1.337^{*}$ & 1.406. & 1.305 & 1.399 & 1.26 & $1.673^{*}$ \\
\hline Care of elders & 1.083 & 0.977 & $1.285^{* *}$ & 0.905 & 0.982 & $1.372 * *$ \\
\hline $\begin{array}{l}\text { Number of family members } \\
\text { met }\end{array}$ & $1.009^{*}$ & 1.011. & 1.007 & $0.946^{* *}$ & 1.014. & 1.013 \\
\hline $\begin{array}{l}\text { Household ratio of adults } \\
\text { SA }\end{array}$ & $3.318 * * *$ & $3.142 * * *$ & $4.325^{* * *}$ & 1.067 & $3.198 * * *$ & $2.544 * * *$ \\
\hline Household ratio of u20 SA & 0.867 & 0.963 & 0.729 . & 0.895 & 0.988 & 0.674 \\
\hline Afraid of neighbourhood & 0.750 & $0.609^{* *}$ & 1.068 & 3.370 & 0.859 & 0.687 \\
\hline $\begin{array}{l}\text { Number of religious } \\
\text { meetings }\end{array}$ & $1.033 * *$ & $1.031 *$ & $1.042 *$ & 0.998 & $1.048 *$ & 0.99 \\
\hline Number of entertainments & $1.187 * * *$ & $1.116^{*}$ & $1.316^{* *}$ & 1.070 & $1.142 *$ & $1.157 *$ \\
\hline Number of restaurants & 1.03 & $1.057^{*}$ & 1.015 & 1.046 & 1.039 & 1.007 \\
\hline Number of social meetings & $1.051 * * *$ & $1.084 * * *$ & 1.013 & 0.876 & 1.033 & $1.07 *$ \\
\hline Public meetings & $1.164 *$ & 1.055 & $1.410^{* * *}$ & $2.915^{* *}$ & 1.245 . & 1.182 \\
\hline Number of friends & 1.009 & 1.006 & 1.012. & 1.02 & 1.004 & 1.001 \\
\hline $\begin{array}{l}\text { Number of acquaintances } \\
\text { met }\end{array}$ & $1.008 *$ & 1.002 & $1.013^{*}$ & $1.032 * *$ & $1.016^{*}$ & 1.008 \\
\hline Voluntary activities & $1.156^{*}$ & $1.274^{* *}$ & 1.043 & 1.682 & $1.301 *$ & 0.954 \\
\hline Work for local society & $1.232 * *$ & 1.208 & $1.290 *$ & $4.489 * * *$ & 0.977 & 1.258 \\
\hline Inactive & 0.974 & 1.097 & 0.780 & 0.136 & 1.105 & 0.680 \\
\hline Retired (not working) & $1.597^{* *}$ & $1.559^{*}$ & 1.562 & 0.0876 & 1.803. & 1.491 \\
\hline Retired but working & 1.416. & 1.336 & 1.405 & 0.660 & 1.681 & 1.213 \\
\hline Inflexible worktime & 1.106 & 1.143 & 1.025 & 0.482 . & 0.988 & 1.042 \\
\hline Managers & $0.715^{*}$ & 1.102 & $0.427 * * *$ & 0.951 & 0.826 & 0.676 \\
\hline Professionals & $0.792 *$ & 0.880 & $0.592 * *$ & 1.66 & 0.752 . & $0.679 *$ \\
\hline Clerical support & 0.815 & 0.903 & $0.602 *$ & 1.173 & 0.799 & 1.194 \\
\hline Service and sales & 0.997 & 0.947 & 1.195 & 0.464 & 0.966 & 1.203 \\
\hline Farmers & $0.685^{* *}$ & 0.901 & $0.439 * * *$ & - & $0.584 *$ & 1.035 \\
\hline Craft workers & 0.864 & 0.777 & 0.819 & 0.372 & 0.758 & 1.146 \\
\hline Plant/machine operators & $0.784 *$ & 0.931 & $0.676^{*}$ & 0.553 & $0.595^{*}$ & 0.766 \\
\hline Elementary occupations & 1.037 & 0.953 & 1.152 & 0.319 & 0.881 & 1.041 \\
\hline Armed forces & 1.523 & 0.541 & 1.476 & 2.996 & 0.458 & 0.648 \\
\hline
\end{tabular}

Note: The table reports odds ratio. Significance: $* * *<0.001, * *<0.01, *<0.05, .<0.1$

There were no farmers belonging to sports clubs in the sample

Source: own study

In term of affluence of expenditures of the household (table 3) the results are consistent with the ones regarding human capital described before. Lack of need to own books lowers odds of SA for women (OR: 0.688, 95\% CI: $0.520,0.910$ ). This effect is seen for respondents previously not engaged in SA (OR: $0.627,95 \%$ CI: 0.428 , 
0.917). Furthermore, SA of women coincides with learning - having obtained new skills within previous two year meant grater odds (OR: 1.261, 95\% CI: 1.006, 1.581).

Table 3. Logistic regression modelling of sport activity (the meso-, exo- and macrosystem variables; disciplines)

\begin{tabular}{|c|c|c|c|c|c|c|}
\hline Variable & $\begin{array}{c}\text { Sports: } \\
\text { whole } \\
\text { sample }\end{array}$ & $\begin{array}{l}\text { Sports: } \\
\text { women }\end{array}$ & $\begin{array}{l}\text { Sports: } \\
\text { men }\end{array}$ & $\begin{array}{c}\text { Sport } \\
\text { clubs: men }\end{array}$ & $\begin{array}{c}\text { Sports: } \\
\text { passive in } \\
2013\end{array}$ & $\begin{array}{l}\text { Sports: } \\
\text { active in } \\
2013\end{array}$ \\
\hline No need for books & $0.703 * *$ & $0.688 * *$ & 0.749 . & 0.205 & $0.627^{*}$ & 0.809 \\
\hline Income (household) & 0.984 & 0.985 & 0.978 & 0.973 & $0.946 * *$ & 0.975 \\
\hline Health benefits & $1.282 *$ & 1.155 & 1.402 . & 1.809 & 1.322 & 1.243 \\
\hline No washing machine & 1.223 & 1.069 & 1.119 & $11.420 *$ & 1.659 & 1.864 \\
\hline No paid TV & 0.879 & 0.816 & 0.900 & $0.239 *$ & 0.844 & 1.183 \\
\hline No separate apartment & 1.290 . & 1.175 & 1.624. & 1.163 & 1.059 & 1.320 \\
\hline Social assistance & 0.874 & 1.023 & $0.679 *$ & 1.713 & 0.804 & 0.710 \\
\hline Educated her/himself & 1.175 & 1.155 & 1.146 & 0.802 & 1.036 & 1.149 \\
\hline New skills & $1.245^{* *}$ & $1.261 *$ & 1.224 & 0.929 & 0.905 & 1.338 \\
\hline Number of other organisations & $1.208 * *$ & 1.050 & $1.483 * *$ & $0.589 *$ & 1.056 & $1.487 * *$ \\
\hline Trust, neighbours & 0.873 & 0.862 & 0.859 & 2.071 & 0.814 & 0.830 \\
\hline Trust, social security & 0.910 & 0.895 & 0.981 & 0.667 & $0.723 * *$ & 0.868 \\
\hline Number of stadiums & 1.021 & 0.998 & 1.047 & 0.988 & $1.088^{*}$ & 0.976 \\
\hline Number of gyms & 0.968 & 0.970 & 0.99 & 1.604 & 1.027 & 0.947 \\
\hline Number of courts & 1.004 & 1.030 & 0.972 & $1.587 * *$ & 0.994 & 1.068 \\
\hline Number of golf courses & $0.990 *$ & $0.985^{*}$ & 0.992 & 0.994 & 0.983 & 0.984 . \\
\hline Number of swimming pools & 1.033 & 0.999 & 1.097 & $0.461 *$ & $1.232 *$ & 0.936 \\
\hline Number of horse tracks & 0.995 & 0.963 & 1.042 & 0.796 & 1.023 & 0.983 \\
\hline Number of shooting & 1.018. & 1.022 . & 1.012 & 0.959 & 1.017 & 1.009 \\
\hline Number of winter & 0.992 . & 0.993 & 0.989 & 0.950 . & 0.985 . & 0.987 \\
\hline Number of motorsports & 1.006 & 0.978 & 1.046. & 0.934 & 0.981 & 1.015 \\
\hline Number of outdoor & $1.019^{*}$ & 1.019 & 1.012 & 0.929 & 1.012 & 1.012 \\
\hline Number of Orliki & $0.961^{*}$ & 0.963 & 0.971 & $1.322 *$ & $0.894 * *$ & 1.037 \\
\hline Large city (>500k) & 0.997 & 0.989 & 1.085 & 3.48 & 0.703 & 0.838 \\
\hline Big city $(>200 \mathrm{k})$ & 1.228 . & 1.131 & 1.389 . & 1.586 & 1.155 & 1.25 \\
\hline Medium city $(>100 \mathrm{k})$ & 1.156 & 1.044 & 1.321 & 0.96 & 0.983 & 1.074 \\
\hline Small city $(>20 \mathrm{k})$ & $1.318 * * *$ & 1.195. & $1.593 * * *$ & 0.574 & 1.293. & 1.188 \\
\hline Town $(<20 \mathrm{k})$ & 1.11 & 0.911 & $1.482 * *$ & 1.163 & 0.843 & 1.398. \\
\hline Lower Silesian & 1.13 & 1.271 & 1.018 & 3.557 & 0.859 & 2.279 \\
\hline Kuyavian-Pomeranian & 1.225 & 1.493. & 0.78 & 0.419 & 1.205 & 1.131 \\
\hline Lublin & 0.976 & 1.188 & 0.711 & 1.965 & 0.797 & 1.195 \\
\hline Lubusz & 1.035 & 1.333 & 0.729 & 1.292 & 1.248 & 1.359 \\
\hline Łódź & 1.089 & 1.179 & 0.829 & 1.16 & 0.828 & 1.281 \\
\hline Lesser Poland & 1.126 & 1.418 & 0.776 & 6.516 & 0.816 & 1.678 \\
\hline Masovian & 0.986 & 1.284 & 0.626 . & 2.809 & 0.759 & 1.212 \\
\hline Opole & 1.021 & 1.181 & 0.86 & 31.36. & 0.392 . & 1.853 \\
\hline Subcarpathian & 1.209 & 1.523 & 0.734 & 3.322 & 0.419 & 2.462 \\
\hline Podlaskie & 0.922 & 1.462 & $0.447^{*}$ & 6.079 & 0.773 & 1.853 \\
\hline Silesian & 0.999 & 1.347 & 0.61 & $16.37 *$ & 0.669 & 1.687 \\
\hline Świętokrzyskie & 0.875 & 1.109 & 0.57 & 4.61 & 0.809 & 0.928 \\
\hline Warmian-Masurian & 1.151 & $1.973 *$ & $0.488^{*}$ & 3.456 & 0.883 & 1.603 \\
\hline Greater Poland & 0.953 & 1.167 & 0.663 & 2.267 & 0.644 & 1.135 \\
\hline West Pomeranian & 1.044 & 1.315 & 0.756 & 0.146 & 1.404 & 0.918 \\
\hline
\end{tabular}

Note: The table reports odds ratio. Significance: $* * *<0.001, * *<0.01, *<0.05, .<0.1$

Source: own study 
Furthermore, for previously passive respondents, level of household income is negatively related to SA - 1,000 PLN a month more per household means 5\% lower odds (OR: 0.595, 95\% CI: 0.909, 0.985). On the other hand, men from households that receive social assistance odds were also lower (OR: 0.679, 95\% CI: 0.468, 0.985).

For men, there was a $48.3 \%$ increase in odds of SA with each organisation to which a respondent belonged to (OR: 1.483, 95\% CI: 1.171, 1.878). This effect takes place for the previously active ones (OR: 1.487, 95\% CI: $1.119,1.976)$. The opposite is true for the active membership of sports clubs (OR: 0.589, 95\% CI: 0.377, 0.920). Moreover, trust towards the social security system is associated with lower odds of initiating SA while passive before (OR: $0.723,95 \%$ CI: $0.581,0.898$; it is worth pointing out that, within the sample, people declaring trust towards the social security system are, on average, five years older than those who do not).

Majority of the types of the sports infrastructure availability at the NUTS 3 level does not explain differences in propensity for SA. Furthermore, with the possible exception of Orliki, the incidental significance of particular measures points to the conclusion that infrastructure seems to be of no particular relevance to SA. Nevertheless, availability of swimming pools raised SA among previously passive people ( $23.2 \%$ increase with increase by 1/100k people; OR: $1.232,95 \%$ CI: $1.025,1.482)$ as well as stadiums $(8.8 \%$ increase with increase by $1 / 100 \mathrm{k}$ people; OR: $1.088,95 \%$ CI: 1.010, 1.173), whereas the opposite seems true for Orliki $(10.6 \%$ decrease with increase by 1/100k people; OR: 0.894, 95\% CI: 0.833, 0.959).

Membership of sports clubs seems to be affected by the availability of sports infrastructure differently - it coincides with availability of courts $(58.7 \%$ increase in odds with increase in relative number by $1 / 100 \mathrm{k}$ people; OR: $1.587,95 \%$ CI: $1.144,2.201)$ and Orliki (OR: 1.322, 95\% CI: 1.047, 1.670). The opposite is true for swimming pools (OR: $0.461,95 \%$ CI: $0.215,0.988$ ).

The regional (voivodeship, NUTS 2) patterns of sport activity are different for both genders. For women, living in the Warmian-Masurian Voivodeship meant greater odds (OR: 1.973, 95\% CI: 1.104, 3.526). For men, Podlaskie (OR: 0.447, 95\% CI: 0.236, 0.847) and Warmian-Masurian (OR: 0.488, 95\% CI: 0.246, 0.969) voivodeships mean significantly lower propensity for SA than the reference point (Pomeranian Voivodeship). A situation with sport clubs differs - the southern Silesian Voivodeship differs significantly from the reference one (OR: $16.37,95 \%$ CI: $1.417,189.079)$

Furthermore, in case of men there is a significant relationship between place of living and SA. The odds of SA increase for men living in small cities (OR: 1.593, 95\% CI: 1.253, 2.025) and towns (OR: 1.482, 95\% CI: 1.136, 1.933), compared to people living in rural areas (which constitute a reference category).

\section{Discussion}

Physical activity and sport play a significant role in developed, modern societies. Due to their multidimensional character, they are factors supporting the development of individuals, as well as the whole communities. Looking from that perspective, contemporary sport is not only an individual concern but appears as a key public health issue. The development, assessment and coordination of strategies to increase SA require an understanding of the individual human behaviour and the impact of various factors on these behaviours (Eime et al., 2017). Therefore, it is necessary to look not only at individual or socio-demographic characteristics, but also at the entire environment, as on the overlapping layers: from individual factors to the macrosystem (Bronfenbrenner, 1979; Damon \& Lerner, 2008). The results of this study show that among the individual factors, age is an important determinant of SA variability and this is in line with previous reports. The likelihood of sports activity decreases with age by $1.5 \%$ with each subsequent year of life. According to studies worldwide, this tendency begins at the age of 13-15 and lasts until 33 years of age (probability decrease by $0.3 \%$ in every year of life) (Hoekman, Breedveld \& Kraaykamp, 2016) and after that the relationship is reversed (Breedveld et al., 2011). At about 50 years of age an increase in physical activity is noted (Klein, 2009) then the active fraction decreases with age again (Scheerder \& Vos, 2011). In our study, a negative relationship and a similar 
odds ratio valuation was proven in women and men subgroups, though it seems to be stronger for the latter, perhaps conforming to a different profile of engagement of men in sports, on one hand, and stronger negative impact of age on general level of activity of men, visible i.e. in generally deactivating effect of retirement - as reported by Biernat et al. (2019)._We have also tested specifications with quadratic and cubic functions of age, but for all of them odds of SA decreased with age for the age range covered by our sample, so the final models contain only non-transformed age variable. It is also worth noting that while the 'woman' dummy itself is not significant in the pooled model, the differences in the impact of the other characteristics emphasize the substantial dissimilarity in determining SA between genders.

Education correlates with SA positively - consistently with existing empirical results (Hoekman, Breedveld \& Kraaykamp, 2016; Grima et al., 2017) - but only for men. Each year of education increases odds by 7\%, while being able to use English language by $26 \%$. The Body Mass Index (BMI) is also an individual factor that correlates with SA of the respondents. Ball et al. (2000)_count it as a lifestyle factor. The odds ratio of SA gets $2.3 \%$ lower for women when BMI increases by a unit, while for men the effect is insignificant, probably reflecting different natures of sports training for most women (more often leading just to losing weight (Hedblom, 2009; Allender, Cowburn \& Foster, 2006; Cerar et al., 2017). and men (often targeting mass increase (Yi-Hsiu \& Chen-Yueh, 2013; Reischer \& Koo, 2004). Generally, health factors seem to be much more important for determining SA of women than or men - this is confirmed e.g. by Casey et al. (2017) and Allender, Cowburn \& Foster (2006). A detailed analysis shows that SA coincides with higher satisfaction with one's health for women (increase in 1 in the reversed scale of $1-7$, means fall in odds by $15 \%$ ). For more detailed health aspects, however, the relation is often reversed. It seems that relatively minor problems with health might stimulate taking up PA by women. In particular, they tend to be active more often, when: sometimes (but not often!) had suicidal thoughts, were seriously ill the previous year, at least once in the recent months had health problems that made it difficult to perform everyday activities or to take part in other activities, had attacks of excessive sweating for more than 15 days a month. On the other hand, shortness of breath decreases odds of SA, as well as being often tired without relation to work. For men, often having ailments making it difficult to leave home, climb stars etc. lower odds of engaging in SA. Also, men tend to be less active when they are losing interest in sex, showing that SA often coincides with other types of PA - Butt (1990) showed that the understanding of sexual activity as a physical activity occurs, and is positively impacting on health and wellbeing. The results confirm that the self-rated early bird people have a more active sex life and more active hobbies. They were more likely to enjoy walking and hiking, playing sports and exercising in a gym - the survey of a 2,000 Americans_(Sleepopolis study, 2019). Similarly, the English study among over 6,800 adults on the average age of 65 , found that any type of sexual activity gave a boost to both men and women, but the intercourse itself was more important for older men (Beech et al., 2018). In our study, it seems that while minor health problems (e.g. illness in the previous year) of women motivate them to activate themselves, men deactivate themselves after such issues (e.g. physical problems) arise. Moreover, active membership in sports clubs seem to result in more significant health problems (often chest/heart pains) for men. Hands \& Parker (2016) claim that men and women gain different health benefits depending on the level, mode and intensity of physical activity. Some of the potential consequences of gender differences in health outcomes are evident in the occurrence of hypokinesis throughout the lifespan.

As shown, an important determinant of SA is smoking. The SA odds for both genders go down by $2.3 \%$ for each cigarette smoked per day. In the context of health behaviour, somewhat surprisingly (Haaland, 2019), overusing alcohol using drugs or designer drugs have no significant effect on SA. Furthermore, while there is no significant relationship between time spending on computer and SA (not shown), there is a positive correlation with time spent on reading newspapers and magazines, once again showing the importance of education.

In addition to sociodemographic threats, psychological conditions and individual attitudes are the strong intrapersonal determinants of participation in sport (Deelen, Ettema \& Kamphuis, 2018). In terms of life 
attitudes, there seems to be no clear relation with SA. Tendency of women to be active more often when they think that achieving goals is more important than having fun suggests the importance of patience (Ghafurian, 2016). On the other hand, active women's more often agreeing that 'a lot of fun is the most important thing in life' suggests significance of lifestyle factors for SA (Allender, Cowburn \& Foster, 2006; Borgers, Thibaut \& Vandermeerschen, 2013). The fact that being 'delighted' or 'pleased' with one's entire life decreases the odds of SA for women, along with the connection to suicidal thoughts, might show that SA is treated by (at least some of) them as an uplifting activity - confirmed by Veenhoven's research (2007).

Conversely, no significant results for men and attitudes have been found except for positive relation between SA and having undiminished energy to work, showing that SA and other significant parts of life can reinforce each other in terms of the attitude (either through beneficial effects of SA or its demands). Physically active Australians found that to believe and self-convince to the regular physical activity, it is necessary to experience the benefits (VicHealth Study, 2017).

The analysis of the next layer's (microsystem) impact on respondents' SA shows that while in case of the marital status, the negative effect is clear and strong for men, number of children in the household has a negative impact only in case of women - this is in line with the literature (Grima et al., 2017; Downward, Lera-López \& Rasciute, 2014). The odds of SA decrease for each child, showing the asymmetric impact of household chores (for older children/teenagers the effects were insignificant). This is reinforced by an observation that for the older children the effect comes rather from inducing previously active respondents to cease SA. According to Wheatley and Bickerton (2016)_childcare is a time constraint for younger adults. For older adults, it is rather caring for other relatives. Along with aging of populations in developed countries, the significance of this constraint will increase.

In case of number of adults, the negative effect is seen for both genders, with a strong for women possibly offsetting the stronger effect of the marital status for men. There is disagreement in the literature in relation to marital status. The study by Hallal et al. (2003) showed that living without a partner (for women) was associated with greater overall lack of physical activity. Dias-da-Costa et al. (2005) proved that lower activity was related to the living with a partner, and Schneider \& Becker (2005) showed that higher physical activity was associated with being single. However, in a Peruvian adults' study (Seclén-Palacín \& Enrique, 2003), living with a partner was associated with the practice of physical activity. The care duties also negatively impacted the regular sport activity (Ruseski et al., 2011). Our findings proved that SA means greater engagement in family life - men that feel responsible for welfare and care for elder parents or other relatives have $28 \%$ higher odds of SA. Interestingly, higher education of father has a much stronger impact than the education level of the respondents themselves. That indicates the high importance of parental lifestyle patterns in terms of spending leisure time actively (Jago et al., 2010). Moreover, with every member of family met regularly, the odds of SA for women go up by $1 \%$. This is consistent with the well-known fact that the family can be a trigger for general activation for women in that case (Grima et al., 2017; Downward, Lera-López \& Rasciute, 2014). A 'contagion' effect (Ross, 2000) between adults is also visible - for women in households in which all the other people over 19 are active the odds of SA are more than three times bigger than for household in which there is no other adult being active, while for men more than four times bigger.

Finally, the number of family members regularly met by men is negatively related to their membership of sports clubs, further suggesting that sports clubs are more time demanding.

In general, being engaged in SA more often than not means also having an active social life - odds rose for both genders for each instance (per month) of going out to religious meetings a cinema, theatre, for a concert, and for women, to a restaurant, café or a pub, and to social meetings. Borgers et al. (2013) and Allender et al. (2006) pointed this out before, by claiming that women are attracted to sport by social interaction and pleasure. Also, more formal social activities were positively related to SA - taking part in public meetings (not related to work), voluntary activities and working for the benefit of local communities. Furthermore, for every acquaintance met 
by men regularly odds of SA rose. According to many studies (Eime et al., 2010; Casey, Eime \& Payne, 2009), spending time with friends makes to start SA easier.

For women, safe social environment is important - often having fears because of crime, drug addiction and hooliganism in one's district, housing estate or neighbourhood meant 39\% lower odds. Local area safety is an important determinant of SA (Hoekman, Breedveld \& Kraaykamp, 2016; Kamphuis, 2013; Beenackers, Kamphuis \& Burdorf, 2011). People who do not feel well and safe in their neighbourhood are more likely not to play sports (Eime et al., 2010; Casey, Eime \& Payne, 2009). This is especially important for the elderly, although it must be admitted that it also strongly depends of sport's type (Barnett, Barnett \& Nathan, 2017). However, there is also research showing no relation between neighbourhood safety and SA (Sugiyama et al., 2009; Poortinga, 2006).

Unlike with family members, being a member of a sports club - similar to Biernat et al. (2019) - was positively related to the number of regularly met acquaintances, which might result directly from attending club. This social role of sports clubs is strengthened by positive relations to participation in public meetings (odds almost triple), but also working for the benefit of local communities (odds more than quadruple).

The apparent lack of importance of the labour market status suggests complex relations of the latter with SA. One clear result - retired women having 56\% higher odds of SA, is optimistic - especially in the context of reports showing that the decline in work-related PA (after retirement) is not compensated by an increase in leisure time physical activity (LTPA) (Troiano et al., 2008; Davis \& Fox, 2006; Henkens, van Solinge \& Gallo, 2008). According to studies worldwide, more than a half of the elderly (52\%) do not get involved in LTPA (Barnes, 2007) - despite that objectively, after retirement, the possibilities of being more physically active are greater. Part of the effects describing labour market (but also education, income or workplace) for men can be seen in the set of variables describing the occupational group. As shown both 'higher' groups (Managers and Officials; Professionals) and 'lower' (Clerical support, Plant/machine operators and Farmers) have lower odds of SA. This is quite confusing considering Biernat et al. (2016) research. These Authors showed that the frequency of inactive adults from upper and lower classes varies respectively from $14.3 \%$ to $36.2 \%$. This suggests that propensity for SA of men is strongly influenced both by time constraints and income (or, in broader terms, lifestyle) constraints. Interestingly, the negative effect for the 'higher' groups is stronger for previously active respondents (suggesting that with more time before these men were active), while for the 'lower' ones only through previously passive (showing that the minimal affluence level might not have been reached). A similar effect was not seen in case of women.

The analysis of the influence of mesosystem factors on the SA of respondents indicates consistency with the results regarding human capital. Lack of need to own books lowers odds of SA for women (but also both genders taken together). Importantly, this effect is stronger for people not engaged in sports activity before, which suggests the impact is a long-term one and approximating general attitude towards life.

Furthermore, a positive relationship between affluence and SA is visible, even if income of household does not have a significant effect (apart from the significant negative effect on previously passive respondents $-1,000$ PLN more a month per household means 5\% lower odds of starting SA - which might suggest that, while a certain level of income is necessary to engage in SA (Hoekman, Breedveld \& Kraaykamp, 2016; Grima et al., 2017), high-income individuals might engage in SA to a limited extent). Men from poorer household - receiving social assistance - had lower odds to be active.In societies wealthier than Polish one, high income increases the likelihood of participation in sport (Lechner \& Sari, 2015; Lechner, 2009; Downward, 2007). However, according to Lera-López and Rapún-Gárate (2011), after becoming involved in sport, this factor loses importance. Therefore, the results are less clear in case of sports clubs, perhaps indicating extra-financial reasons behind.

Further, SA coincides with gaining new skills by women. Therefore, it seems that either greater flexibility or willingness to invest in own future play a role here, dominating a possible substitution effect. This is confirmed 
by the concept of Delayed Gratification by Mischel (1974), which is associated with resisting a smaller but more immediate reward in order to receive a larger or more enduring reward later. Many studies inclined to link the ability to delay gratification with several positive outcomes, i.e. self-rated physical and mental health, social competences or academic achievements. Results of our study showed, that the engagement in formalised cooperation is positively associated with SA of men in the form of number of organisations to which they belong to, once again showing positive association between different forms of activity. In case of sports clubs, once again a substitution effect emerges - with each other organization the odds decrease substantially. It supports the observation that the sports clubs in Poland are rather associated with striving for sport success, but not social values (Elmose-Østerlund et al., 2017). Moreover, trust towards the social security system is associated with lower odds of initiating SA while passive before (it is worth pointing out that, within the sample, people declaring trust towards the social security system are, on average, five years older than those who do not).

Analysis of the latest layers - the exosystem shows, that at the most general level, sports infrastructure does not contribute much to SA. The literature review showed mixed results about that issue (Eime et al., 2017)._For the general population, similarly to Grima et al. (2017), outdoor facilities seem to boost SA. Furthermore, within the Orliki initiative facilities seem to have been located in regions with relatively low SA. Interestingly, swimming pools seemed effective in raising SA among previously passive people. Quite surprisingly, to lesser extent stadiums did as well, whereas the opposite seems true for Orliki (one has to remember, that they were constructed before 2013, when the previous SA was measured; therefore, the result suggests that they are mostly built in regions having problems with mobilising people to engage in SA). These results give some indication for deisgners of programs focused to increase participation in sport. However, it should be considered that participation may depend on the type of sport and the facility (Wicker, Hallmann \& Breuer, 2012). Especially that nowadays there is a slow leave from team sports, but in favor of individual disciplines, including outdoor sport activities (Borgers, Thibaut \& Vandermeerschen, 2013) - which requires a different infrastructure. Our results, once again, pointed out that the process of determining active membership of sports clubs is qualitatively different to the outside sport club SA - the former coincides with availability of courts and Orliki facilities. This is in line with the result of Elmose-Østerlund (2017), who show that in Poland the reliance of the sports clubs on public infrastructure is relatively high. The opposite is true for swimming pools, which points to a thoroughly individual nature of the discipline.

SA is also influenced by the macrosystem. However, the regional (voivodeship, NUTS 2) patterns of sport activity are different for both genders. In particular, the for women, the Warmian-Masurian in the North East seem to align with the highest SA odds and the Northern Pomeranian with the lowest, while for men the situation is the opposite. However, there seems to be no underlying explanation for this effect based on the regional economic development, urbanisation nor climate differences. A situation with sport clubs differs. In particular, a difference between Northern and Southern Poland can be observed - membership is much more common in the southern Silesian, even more when compared to other Pomeranian ones. This observation is consistent with official data by Statistics Poland on membership of sports clubs (Statistics Poland, 2019).

Lastly, higher odds of SA for men living in small cities and towns, compared to people living in rural areas, with especially substantial difference in comparison to large cities, is, to some extent, consistent with the observation regarding occupations and income. Once again, it is the middle level (in this case in terms of size of the area of living) that is the most conducive to SA. It is important to bear in mind that aspects like occupation, income and education are controlled for, which suggests that cultural and lifestyle differences between different places of living are relevant (Mrazek, Fialova \& Bykhovskaya, 2004).

\section{Conclusions}

A substantial part of our results is consistent with the earlier research in the area. Though comparison of strength of different factors and model specifications allows for drawing conclusions important for understanding the 
process of engagement in SA as a whole life choice. The impact of family (both children, spouses and parents, currently and in the past) is crucial, but more for women. On the other hand, for men factors relating to the labour market are more important. Moreover, relations with attitude and self-reported health differ in genders, which suggests that the role of SA in their life, on average, differs.

In the context of past and future research on relations between sport and social capital, a crucial outcome is that using information on membership of sports clubs as a proxy for SA should be done cautiously. It is, in fact, neither simply a more intensive form of SA, nor a SA with a social context. As our results show, some social activities are limited with active participation in clubs, even though they coincide with SA in general. Therefore, membership of sports clubs does not necessarily correlate with intensified involvement in the society outside the club. This is also consistent with the fact, that sports clubs in Poland are rather associated with striving for sport success, not social values.

The 'hard' measures of promoting SA - sports clubs and sport infrastructure (as the results for the Orliki programme show) are of limited effectiveness. The former was able to attract limited, in scale and scope, subgroups of the society. It confirms the existential threat for sports clubs.

The limitations of our research result mainly came from the nature of the available data. While the rich $S D$ database allowed for inclusion of broad socio-ecological context, its longitudinal nature could be used to a limited extent, allowing only for a partial control of individual heterogeneity, through past SA. Furthermore, the survey is limited to one country and requires careful generalisation of the results due to the inter-country cultural differences. Moreover, all the outcomes are self-reported, so they might be influenced by perceptions of the respondents also when it comes to supposedly objective measures (income or height).

Summarizing, SA and sport clubs' participation give two different adult's profiles. Beside the context of physical activity as a whole life choice, gender seems to be the strongest moderator of the profile. For women - individual and family factors - the first, second and third layer of Bronfenbrenner's model are crucial for SA engagement, but for men factors from the subsequent layers comes important i.e. labour market factors. Creating up-to-date strategies for increasing SA - leading to sport as a whole-life choice, requires consideration of the socio-ecological profile of adult Poles, and acceptance that the traditional tools become irrelevant for some groups or populations.

\section{Ethics approval and informed consent}

This study was approved by the National Science Centre, Poland as a project No. 2017/27/B/HS4/00427 „The role of sport activity in building social capital in Poland".

\section{Competing interests}

The authors declare that they have no competing interests.

\section{Funding}

The study was conducted as part of the project No. 2017/27/B/HS4/00427, „The role of sport activity in building social capital in Poland" funded by the National Science Centre, Poland, and conducted in the Warsaw School of Economics.

The appendices are available on request from the authors. 


\section{REFERENCES}

Allender, S., Cowburn, G., \& Foster, C. (2006). Understanding participation in sport and physical activity among children and adults: a review of qualitative studies. Health Educ Res, 21(6), 826-835. doi: 10.1093/her/cyl063

Ball, K., Crawford, V.D., \& Owen, V.N. (2000). Too fat to exercise? Obesity as a barrier to physical activity Brief Report. Aust N Z J Public Health, 24 (3), 331-333.

Barnes, P. (2007). Physical activity among adults: United States, 2000 and 2005. Hyattsville, MD: US Department of Health and Human Services, Centers for Disease Control.

Barnett, D.W., Barnett, A., Nathan, A., Van Cauwenberg, J., \& Cerin, E. (2017). Built environmental correlates of older adults' total physical activity and walking: a systematic review and meta-analysis. Int J Behav Nutr Phys Act, 14,103. doi:10.1186/s12966-017-0558-z

Becker, G. (1974). A theory of social interactions. J Polit Econ, 82(6), 1063-1093. doi: http://dx.doi.org/10.1086/260265

Beech, S. (2018, December 13). Having an active sex life in your 60s and 70s good for your health. Mirror. Retrieved February 10, 2020 from: https://www.mirror.co.uk/news/uk-news/having-active-sex-life-your-13725943

Beenackers, M.A., Kamphuis, C.B., Burdorf, A., Mackenbach, J.P., \& van Lenthe, F.J. (2011). Sports participation, perceived neighborhood safety, and individual cognitions: how do they interact? International Journal of Behavioral Nutrition and Physical Activity, 8(1), 76. https://doi.org/10.1186/1479-5868-8-76

Biernat, E., \& Buchholtz, S. (2016). The Regularities in Insufficient Leisure-Time Physical Activity in Poland. International Journal of Environmental Research and Public Health, 13(8), 798. https://doi.org/10.3390/ijerph13080798

Biernat, E., Piątkowska, M., Zembura, P., \& Gołdys, A. (2017). Problem zarządzania orlikami z perspektywy animatorów $\mathrm{z}$ gmin wiejskich i miejskich [Challenges of management of Orlik pitches in the perspective of the animators from municipal and rural communities]. Przeds Zarz, 18(8), 429-444.

Biernat, E., Skrok, Ł. \& Krzepota, J. (2019). Short-Term and Medium-Term Impact of Retirement on Sport Activity, SelfReported Health, and Social Activity of Women and Men in Poland. BioMed Res Int, Article ID 8383540, https://doi.org/10.1155/2019/8383540.

Borgers, J., Thibaut, E., Vandermeerschen, H., Vanreusel, B., Vos, S., \& Scheerder, J. (2013). Sports participation styles revisited: A time-trend study in Belgium from the 1970s to the 2000s. Int Rev Sociol Sport, 50(1), 45-63. doi: $10.1177 / 1012690212470823$

Breedveld, K., \& Hoekman, R. (2011). Measuring sports participation in the Netherlands -the need to go beyond guidelines. Eur J Sport Sci, 8 (1/2), 117-132. https://doi.org/10.1080/16138171.2011.11687873

Bronfenbrenner, U. (1979).The ecology of human development: Experiments by nature and design. England, London: Harvard University Press.

Bronfenbrenner, U., \& Morris, P.A. (2006). The Bioecological Model of Human Development. In R.M. Lerner, \& W. Damon (Eds.), Handbook of child psychology: Theoretical models of human development (pp. 793-828). Hoboken, NJ, US: John Wiley \& Sons Inc.

Butt, D.S. (1990). The Sexual Response as Exercise. Sports Medicine, 9(6), 330-343. https://doi.org/10.2165/00007256199009060-00002

Casey, M.M., Eime, R.M., Harvey, J.T., Sawyer, N.A., Craike, M.J., Symons, C.M., \& Payne, W.R. (2017). The influence of a Healthy Welcoming Environment on participation in club sport by adolescent girls: a longitudinal study. BMC Sports Sci Med Rehabil, 9, 12. doi: 10.1186/s13102-017-0076-y

Casey, M.M., Eime, R.M., Payne, W.R., \& Harvey, J.T. (2009). Using a Socioecological Approach to Examine Participation in Sport and Physical Activity Among Rural Adolescent Girls. Qualitative Health Research, 19(7), 881-893. https://doi.org/10.1177/1049732309338198

Cawley, J. (2004). An Economic Framework for Understanding Physical Activity and Eating Behaviors. Am J Prev Med, 27, 117-125. doi: 10.1016/j.amepre.2004.06.012

Cerar, K., Kondrič, M., Ochiana, N., \& Sindik, J. (2017). Exercise Participation Motives and Engaging in Sports Activity among University of Ljubljana Students. Open Access Maced J Med Sci, 5(6), 794-799. doi:10.3889/oamjms.2017.159.

Cochrane, T., \& Davey, R.C. (2008). Increasing uptake of physical activity: a social ecological approach. J R Soc Promot Health, 128: 31-40. doi:10.1177/1466424007085223

Council for Social Monitoring. (2015). Integrated database, questionnaires [Data set]. Retrieved February 10, 2020 from: http://www.diagnoza.com/.

Czapiński, J., \& Panek, T. (Eds.). (2015). Social diagnosis. Retrieved February 10, 2020 from http://www.diagnoza.com/ Damon, W., \& Lerner, R.M. (2008). Child and adolescent development: An advanced course. USA, New Jersey: Wiley. 
Davis, M.G., \& Fox, K.R. (2006). Physical activity patterns assessed by accelerometry in older people. European Journal of Applied Physiology, 100(5), 581-589. https://doi.org/10.1007/s00421-006-0320-8

Deelen, I., Ettema, D., \& Kamphuis, C.B.M. (2018). Sports participation in sport clubs, gyms or public spaces: How users of different sports settings differ in their motivations, goals, and sports frequency. PLoS ONE, 13(10), e0205198. https://doi.org/10.1371/journal.pone.0205198.

Dias-da-Costa, J.S., Hallal, P.C., Wells, J.C.K., Daltoé, T., Fuchs, S.C., Menezes, A.M.B., \& Olinto, M.T.A. (2005). Epidemiology of leisure-time physical activity: a population-based study in southern Brazil. Cadernos de Saúde Pública, 21(1), 275-282. https://doi.org/10.1590/s0102-311x2005000100030

Downward, P. (2007). Exploring the economic choice to participate in sport results from the 2002 general household survey. Int Re. Appl Econ, 21(5), 633-653. doi: 10.1080/02692170701474710

Downward, P., Lera-López, F., \& Rasciute, S. (2014). The correlates of sports participation in Europe. European Journal of Sport Science, 14(6), 592-602. https://doi.org/10.1080/17461391.2014.880191

Eime, R.M., Harvey, J., Charity, M.J., Casey, M., Westerbeek, H., \& Payne, W.R. (2017). The relationship of sport participation to provision of sports facilities and socioeconomic status: a geographical analysis. Australian and New Zealand Journal of Public Health, 41(3), 248-255. https://doi.org/10.1111/1753-6405.12647

Eime, R.M., Payne, W.R., Casey, M.M., \& Harvey, J.T. (2010). Transition in participation in sport and unstructured activity for rural living adolescent girls. Health Educ Res, 25(2), 282-293. doi: 10.1093/her/cyn060

Elmose-Østerlund, K., Ibsen, B., Nagel, S., \& Scherder, J. (2017). Explaining similarities and differences between European sports clubs: An overview of the main similarities and differences between sports clubs in ten European countries the potential explanations. Institut for Idræt og Biomekanik, Syddansk Universitet.

European Commission. (2010). Sport and Physical Activity. Special Eurobarometer 334. Brussels: European Commission. Ghafurian, M. (2016). Gender Differences in the Effect of Impatience on Men and Women's Timing Decisions. In Proceedings of the $38^{\text {th }}$ Annual Meeting of the Cognitive Science Society. Philadelphia, PA: Cognitive Science Society.

Green, B.C., (2005). Building sport programs to optimize athlete recruitment, retention, and transition: Toward a normative theory of sport development. J Sport Manage, 19(3), 233-253. https://doi.org/10.1123/jsm.19.3.233

Grima, S., Grima, A., Thalassinos, E., Seychell, S., \& Spiteri, J.V. (2017). Theoretical models for sport participation : literature review. International Journal of Economics and Business Administration, 5(3), 94-116.

Grima, S., Grima, A., Thalassinos, E., Seychell, S., \& Spiteri, J.V. (2018). A Study of the Determinants of Sports Participation by Maltese Nationals. European Research Studies Journal, 21(2), 110-133.

Haaland, M. (2019, March 12). New York Post. Retrieved February 10, 2020 from: https://www.wlu.edu/studentlife/health-and-safety/student-health-and-counseling/health-library/alcohol-and-other-drugs/health-and-behavioral-risksof-alcohol-and-drug-use.

Hallal, P.C., Victora, C.G., Wells, J.C.K., \& Lima, R.C. (2003). Physical Inactivity: Prevalence and Associated Variables in Brazilian Adults. Medicine \& Science in Sports \& Exercise, 35(11), 1894-1900. https://doi.org/10.1249/01.mss.0000093615.33774.0e

Hallmann, K., Wicker, P., Breuer, C., \& Schönherr, L. (2011). Interdependency of sport supply and sport demand in German metropolitan and medium-sized municipalities - findings from multi-level analyses. Eur J Sport Sci, 8 (1/2), 6584. doi: 10.1080/16138171.2011.11687870

Hallmann, K., Wicker, P., Breuer, C., \& Schönherr, L. (2012). Understanding the importance of sport infrastructure for participation in different sports - findings from multi-level modelling. Eur Sport Manag Q, 12(5), 525-544. https://doi.org/10.1080/16184742.2012.687756

Hands, B., \& Parker, H. (2016). Male and Female Differences in Health Benefits Derived from Physical Activity: Implications for Exercise Prescription. Journal of Womens Health, Issues and Care, 5(4). https://doi.org/10.4172/23259795.1000238

Hedblom, C. (2009). The Body is Made to Move. Gym and Fitness Culture in Sweden. Stockholm Universitet. Retrieved February 10, 2020 from: http://www.diva-portal.org/smash/get/diva2:218786/FULLTEXT01.pdf

Henkens, K., van Solinge, H., \& Gallo, W. T. (2008). Effects of retirement voluntariness on changes in smoking, drinking and physical activity among Dutch older workers. The European Journal of Public Health, 18(6), 644-649. https://doi.org/10.1093/eurpub/ckn095

Hoekman, R., Breedveld, K., \& Kraaykamp, G. (2016). Sport participation and the social and physical environment: explaining differences between urban and rural areas in the Netherlands. Leisure Studies, 1-14. https://doi.org/10.1080/02614367.2016.1182201 
Jago, R., Fox, K.R., Page, A.S., Brockman, R., \& Thompson, J.L. (2010). Parent and child physical activity and sedentary time: Do active parents foster active children? BMC Public Health, 10(1). https://doi.org/10.1186/1471-2458-10-194

Kamphuis, C., \& van Lenthe, F. (2013). Socioeconomic Differences in Physical Activity: The Role of Neighbourhood Factors. In C. Stock, A., Ellaway (Eds.), Neighbourhood Structure and Health Promotion (pp. 223-248). Boston, MA: Springer.

Klein, T. (2009). Determinanten der Sportaktivität und der Sportart im Lebenslauf. Kölner Z.Soziol.u.Soz.Psychol (KZfSS Kölner Zeitschrift für Soziologie und Sozialpsychologie), 61 (1), 1-32.

Lechner, M. (2009). Long-run labour market and health effects of individual sports activities. Journal of Health Economics, 28(4), 839-854. https://doi.org/10.1016/j.jhealeco.2009.05.003

Lechner, M., \& Sari, N. (2015). Labor market effects of sports and exercise: Evidence from Canadian panel data. Labour Economics, 35, 1-15. https://doi.org/10.1016/j.labeco.2015.04.001

Lera-López, F., \& Rapún-Gárate, M. (2011). Determinants of sports participation and attendance: differences and similarities. Int J Sport Mark Spo, 12(2), 66-89. https://doi.org/10.1108/IJSMS-12-02-2011-B007

Mischel, W. (1974). Processes in Delay of Gratification. In Advances in Experimental Social Psychology (pp. 249-292). https://doi.org/10.1016/s0065-2601(08)60039-8

Mrazek, J., Fialova, L., \& Bykhovskaya, I. (2004). Individualisation, sport and body on Central and Eastern Europe. In G. Anders, J. Mrazek, G. Norden \& O. Weiss (Eds.), European integration and sport. Münster: Lit-Verlag.

Poortinga, W. (2006). Perceptions of the environment, physical activity, and obesity. Social Science \& Medicine, 63(11), 2835-2846. https://doi.org/10.1016/j.socscimed.2006.07.018

Reischer, E., \& Koo, K. S. (2004). The Body Beautiful: Symbolism and Agency in the Social World. Annu Rev Anthropol, 33, 297-317. https://doi.org/10.1146/annurev.anthro.33.070203.143754

Ross, C. E. (2000). Walking, exercising, and smoking: does neighborhood matter? Social Science \& Medicine, 51(2), 265274. https://doi.org/10.1016/s0277-9536(99)00451-7

Ruseski, J.E., Humphreys, B.R., Hallmann, K., \& Breuer, C. (2011). The interplay of family structure, time constraints, and sport participation. Eur Rev Aging Phys A, 8(2), 57-66.

Scheerder, J., \& Vos, S. (2011). Social stratification in adults' sports participation from a time-trend perspective. Results from a 40-year household study. European Journal for Sport and Society, 8(1/2), 31-44. https://doi.org/10.1080/16138171.2011.11687868

Schneider, S., \& Becker, S. (2005). Prevalence of Physical Activity among the Working Population and Correlation with Work-Related Factors: Results from the First German National Health Survey. Journal of Occupational Health, 47(5), 414-423. https://doi.org/10.1539/joh.47.414

Seclén-Palacín, J.A., \& Enrique, J.R. (2003). Factores sociodemográficos y ambientales asociados con la actividad física deportiva en la población urbana del Perú. Rev Panam Salud Publica, 14(4), 255-26.

Sleepopolis study. (2019). Retrieved February 10, 2020 from: https://nypost.com/2019/03/12/early-risers-have-a-moreactive-sex-life-survey/.

Statistics Poland. (2014). Results of KFT-OB/a, KFT-OB/b, KFT-1 [Data set].

Statistics Poland. (2019). Kultura fizyczna $w$ Polsce $w 2018$ r. Informacje sygnalne /Physical Culture in 2018. Signal information/. Warsaw. Retrieved February 10, 2020 from: https://stat.gov.pl/obszary-tematyczne/kultura-turystykasport/sport/kultura-fizyczna-w-polsce-w-2018-r-,13,2.html.

Sugiyama, T., Leslie, E., Giles-Corti, B., \& Owen, N. (2009). Physical activity for recreation or exercise on neighbourhood streets: associations with perceived environmental attributes. Health Place, 15(4), 1058-1063. doi: 10.1016/j.healthplace.2009.05.001

Troiano, R.P., Berrigan, D., Dodd, K.W., Mâsse, L.C., Tilert, T., \& Mcdowell, M. (2008). Physical Activity in the United States Measured by Accelerometer. Medicine \& Science in Sports \& Exercise, 40(1), 181-188. https://doi.org/10.1249/mss.0b013e31815a51b3

Van Tuyckom, C. (2011). Six sporting worlds. A cluster analysis of sports participation in the EU-25. Quality \& Quantity, 47(1), 441-453. https://doi.org/10.1007/s11135-011-9528-8

Veenhoven, R. (2007). Healthy happiness: effects of happiness on physical health and the consequences for preventive health care. Journal of Happiness Studies, 9(3), 449-469. https://doi.org/10.1007/s10902-006-9042-1

VicHealth Study. (2017). Physical activity across life stages. Retrieved February 10, 2020 from: https://www.vichealth.vic.gov.au/media-and-resources/publications/life-stages. 
Wheatley, D., \& Bickerton, C. (2016). Subjective well-being and engagement in arts, culture and sport. Journal of Cultural Economics, 41(1), 23-45. https://doi.org/10.1007/s10824-016-9270-0

Wicker, P., Hallmann, K., \& Breuer, C. (2012). Micro and macro level determinants of sport participation. Sport, Business and Management: An International Journal, 2(1), 51-68. https://doi.org/10.1108/20426781211207665

World Health Organization. (2018). Global action plan on physical activity 2018-2030: more active people for a healthier world. Retrieved February 10, 2020 from from: https:/www.who.int/ncds/prevention/physical-activity/global-action-plan2018-2030/en/

Yi-Hsiu, L., \& Chen-Yueh, C. (2013). Masculine versus feminine sports: The effects of peer attitudes and fear of negative evaluation on sports participation among Taiwanese college students. Rev Int Psychol Soc, 26(4), 5-23.

\section{AUTHOR'S ADDRESS:}

Elżbieta Biernat

Department of Tourism

Collegium of World Economy

SGH Warsaw School of Economics

al. Niepodległości 162

02-554 Warsaw, Poland

E-mail: elzbieta.biernat@sgh.waw.pl

Received: 23 December 2019; Accepted: 13 February 2020 